Nat. Hazards Earth Syst. Sci., 17, 1697-1711, 2017

https://doi.org/10.5194/nhess-17-1697-2017

(C) Author(s) 2017. This work is distributed under

the Creative Commons Attribution 3.0 License.

\title{
Exploring spatial-temporal dynamics of fire regime features in mainland Spain
}

\author{
Adrián Jiménez-Ruano, Marcos Rodrigues Mimbrero, and Juan de la Riva Fernández \\ GEOFOREST Group, IUCA, Department of Geography and Land Management, University of Zaragoza, \\ Pedro Cerbuna 12, 50 009, Zaragoza, Spain \\ Correspondence to: Adrián Jiménez-Ruano (jimenez@unizar.es)
}

Received: 15 May 2017 - Discussion started: 29 May 2017

Accepted: 25 August 2017 - Published: 4 October 2017

\begin{abstract}
This paper explores spatial-temporal dynamics in fire regime features, such as fire frequency, burnt area, large fires and natural- and human-caused fires, as an essential part of fire regime characterization. Changes in fire features are analysed at different spatial - regional and provincial/NUTS3 - levels, together with summer and winter temporal scales, using historical fire data from Spain for the period 1974-2013. Temporal shifts in fire features are investigated by means of change point detection procedures - Pettitt test, AMOC (at most one change), PELT (pruned exact linear time) and BinSeg (binary segmentation) - at a regional level to identify changes in the time series of the features. A trend analysis was conducted using the Mann-Kendall and Sen's slope tests at both the regional and NUTS3 level. Finally, we applied a principal component analysis (PCA) and varimax rotation to trend outputs - mainly Sen's slope values - to summarize overall temporal behaviour and to explore potential links in the evolution of fire features.

Our results suggest that most fire features show remarkable shifts between the late 1980s and the first half of the 1990s. Mann-Kendall outputs revealed negative trends in the Mediterranean region. Results from Sen's slope suggest high spatial and intra-annual variability across the study area. Fire activity related to human sources seems to be experiencing an overall decrease in the northwestern provinces, particularly pronounced during summer. Similarly, the Hinterland and the Mediterranean coast are gradually becoming less fire affected. Finally, PCA enabled trends to be synthesized into four main components: winter fire frequency (PC1), summer burnt area (PC2), large fires (PC3) and natural fires (PC4).
\end{abstract}

\section{Introduction}

Wildfire is a disturbance affecting many ecosystems on a global level. Fire itself is a very dynamic landscape process, which depends on different factors, such as weather, vegetation type and structure, fuel moisture, land use and human activity (Falk et al., 2011). Understanding wildfire phenomenon is still a challenging task, especially when facing climate and/or socioeconomic changes (Pausas and Keeley, 2009) as is the case of Spain (Pausas, 2004; Pausas and Fernández-Muñoz, 2012; Turco et al., 2014) and other EUMed regions (Moriondo et al., 2006; Salis et al., 2014; Venäläinen et al., 2014). In this context, fire regime characterization may contribute to improving our knowledge on how wildfires generally behave. For example, understanding spatial and temporal patterns of wildfire features may lead to more effective management strategies or prevention policies.

Improved understanding of fire regimes may be achieved by providing deeper insights into the spatial patterns of fire regime features over a certain period of time (i.e. homogenous areas with similar fire regime characteristics). From a temporal perspective, previous studies reported the existence of temporal changes or trends in the evolution of several fire regime features (Flannigan et al., 2009; Rodrigues et al., 2013; Turco et al., 2016). However, despite there being evidence of temporal variability in fire regime features, it is not usually considered when defining, characterizing or outlining fire regimes. The concept of fire regime is commonly defined as the average conditions of fire that remains recurrent and consistent within a particular area and occurring over a certain period of time (Krebs et al., 2010). According to this definition, it seems clear that both space and time are taken to be stationary, but fire regime components are 
in fact highly variable across time and space (Morgan et al., 2001). Recently, several works studying fire regimes were conducted in Spain, among which those by Moreno and Chuvieco (2012) and Moreno and Chuvieco (2016) are notable as the latest attempts to deal with fire regime characterization. However, in these works, the behaviour of fire regime features is still assumed to be homogeneous or stationary over time. To our understanding, the concept or definition of fire regime has to include changes in fire features over the study period. This is ultimately the goal of our proposal: to characterize the temporal evolution of fire regime features so that they can be employed to refine and improve the spatial outline of fire regimes, for example, by using trend outputs as an additional input of the cluster or zoning algorithm.

Analyses of spatial-temporal trends of fire regime features are common in the literature. The most widespread approach addresses changes in fire frequency and burned area (Kasischke and Turetsky, 2006; Pausas and Fernández-Muñoz, 2012; Rodrigues et al., 2013; Zavala et al., 2011). In the Mediterranean region, the main findings indicate a general decrease during the period 1985-2011 (Turco et al., 2016) in the annual number of wildfires and burned area, although a certain spatial variability is observed in the trends. For instance, over the last few decades, the burned area in Spain has decreased. Conversely, the yearly number of fires has increased, except on the Mediterranean coast (Turco et al., 2016). However, most studies focus mainly on analysing "generic" fire (number of fires and burned area). This is particularly true for Spain, which lacks a detailed analysis of fire trends based on a spatial-temporal approach. We believe that a proper characterization of fire regime must take into account additional features, such as fire size, cause or seasonality. Even though some studies dealing with the temporal dimension of wildfires do exist (Serra et al., 2013), most of them present some limitations, such as a short time series (less than 20 years of data). Meanwhile, analyses using a longer time series do not include many fire regime features and stay with the overall number of fires and burned area (Pausas, 2004; Pausas and Fernández-Muñoz 2012; Moreno et al., 2014). Specifically, we stress the importance of assessing the evolution of large fires (fires with more than 500 ha burned; San-Miguel-Ayanz et al., 2013) and the potential differences relating the ignition source of a wildfire, either natural or human caused.

Therefore, the analysis of the temporal dimension of fire regime features must be extended to these other features in order to provide a more detailed picture of the evolution of fire activity with the ultimate goal of characterizing fire regimes. Similarly, advances must be made in applying trend detection procedures. Determining whether a certain feature changes significantly is useful but not sufficient. Further insights into trend magnitude must be provided so that we can compare trends among several regions and explore possible relationships among temporal changes in fire features.
The aim of this study is to analyse spatial-temporal trends of several fire features during the period 1974-2013 and explore potential relationships among those detected. In addition, this work would also allow progress and further developments in the fire regime zoning. The analysis is conducted at several spatial, such as regional and NUTS3/provincial level, and autumn-winter and springsummer temporal scales in mainland Spain. Data on fire regime features were retrieved from historical fire records stored in the EGIF (General Wildfires Statistics) database. Firstly, seasonal shifts in the evolution of fire feature were examined using change point detection techniques in three different regions comprising the whole of mainland Spain. We used several checkpoint techniques to determine if and when significant changes in the temporal evolution of each fire regime feature takes place. Trend detection procedures were then applied at the two different spatial levels to address the spatial-temporal variability of each fire feature. The purpose was to determine whether fire features vary over time and, if so, its sign - upward or downward - and strength. Finally, complementary analyses were applied to uncover potential links in the evolution of fire features.

\section{Study area}

The study area encompasses the whole of mainland Spain (thus excluding the Balearic and Canary archipelagos and the autonomous cities of Ceuta and Melilla). Spain is very biophysically diverse, presenting a wide variety of climatic, topographical and vegetation communities. This diversity also appears when discussing socioeconomic conditions in terms of settlement systems and population structure, production sector, changes in land use and land cover, or structure of the territory.

From a climatic perspective, mainland Spain is characterized by contrasting climatic conditions. According to the Spanish Climate Atlas (AEMET, 2011) and based on the Köppen-Geiger climate classification system (last version from 1936) we found cold (D), temperate (C) and dry (B) climates. Csa (temperate with dry or hot summer) is the type of climate which covers most of the Iberian Peninsula, occupying approximately $40 \%$ of its surface. It covers the majority of the southern central plateau region and the Mediterranean coastal regions, with the exception of the arid zones in the southeast, where we found BWh (hot desert) conditions. Cold climates are located in the highest mountain ranges in both the Pyrenees and Iberian mountain ranges (Dfb-c) and also in small areas of the mountainous regions at higher altitudes in the Cantabria Mountains, the Iberian mountain ranges, Central Ranges and the Sierra Nevada (Dsb-f). Finally, Cfa (temperate with a dry season and hot summer) is mainly seen in the northeast area, within an area of medium altitude which surrounds the Pyrenees and the Iberian mountains. 
From a biogeographical point of view, mainland Spain is divided in two biogeographical regions: Eurosiberian, located in the northwestern area, and the Mediterranean, covering the remaining area. The Eurosiberian area is mostly covered by various types of vegetation from deciduous oak and ash to evergreen oak woodlands (Quercus robur, Fraxinus excelsior or Fagus sylvatica), but this region also has a quite important component of forest plantations such as Pinus radiata and Eucalyptus globulus. In turn, the Mediterranean region presents complex mosaics of agricultural systems and plant communities. Sclerophyllous and evergreen vegetation, such as Quercus ilex, Quercus suber and thermophilous scrublands (maquis and garrigue formations), dominate the region. Forest areas mainly consist of pine species (Pinus halepensis, Pinus sylvestris, Pinus nigra, Pinus pinea or pinaster). Furthermore, bioclimatic (altitudinal) belts exist within each region in mountain areas such as the Pyrenees along the French border or Sierra Nevada on the southern Mediterranean coast.

Due to the variety of landscapes, climate and socioeconomic conditions, three different regions - Northwest (NW), Hinterland (HL) and Mediterranean (MED) - were outlined (Fig. 1), following the criteria established by the Spanish Environmental Ministry in their annual fire reports (MAGRAMA, 2002, 2007, 2012). These regions portray homogeneous areas in terms of wildfire activity by merging entire provinces or autonomous communities and have been previously used on other recent works like Moreno et al. (2014). The spatial coverage of these regions is similar to other zoning proposals like Sousa et al. (2015) or Trigo et al. (2016), being also based on NUT3S aggregations, although they include Portugal as well. The NW region includes the autonomous communities of Galicia, Asturias, Cantabria and the Basque Country, as well as the provinces of León and Zamora. This region is located within the Eurosiberian region, excluding the Pyrenees. The HL region includes all of the autonomous communities without coastline, except for the provinces of León and Zamora (included in the NW region). This region is located in the transition boundary between the Mediterranean and Eurosiberian regions, thus sharing characteristics in terms of climate influence and plant species. Finally, the MED region, situated within the Mediterranean biogeographical region, includes all the autonomous communities along the Mediterranean coast.

\subsection{Fire data}

Fire records from 1974 to 2013 were collected from the EGIF database and fire count data, the size of the total burned area, ignition triggering date and fire cause were retrieved for each fire event, later summarized by season at NUTS3 level. Only information on fires larger than 1 ha was retained because small fires (i.e. fires with less than 1 ha affected) were not fully compiled until 1988. This is a well-known issue affecting other regions in the Mediterranean as Portugal (Pereira et al., 2011). Additionally, it is important to remember that in the case of the autonomous community of Navarre, fire data were only available from 1988. Hence, all the analyses conducted in Navarre were based on a slightly different study period (1988-2013).

In addition to NUTS3 level, we also included a regional scale of aggregation, together with two different fire seasons. Thus, annual data were split into a spring-summer season (S) from April to September and an autumn-winter season (W) from October to March. From all available fire data information (see Table 1), eight fire features were then constructed for each fire season, NUTS and region:

- Number of fires $(\mathrm{N})$ : total number of events, regardless of size or ignition source.

- Burned area size (B): total fire affected area, regardless of size or ignition source.

- Number of large fires (N500): number of fires above 500 ha burned, regardless of ignition source.

- Burned area from large fires (B500): overall affected area from fires above 500 ha, regardless of ignition source.

- Number of natural fires (NL): number of fires triggered by lightning.

- Burned area from natural fires (BL): overall burned area from fires triggered by lightning.

- Number of human fires (NH): number of fires triggered by an anthropogenic source.

- Burned area from human fires (BH): overall burned area from fires triggered by an anthropogenic source.

\section{Methods}

The methodology consisted of three stages. First, we explored changes in the temporal evolution of fire features by means of the Pettitt test and change detection procedures on a regional scale. Second, a trend detection analysis was conducted using the Mann-Kendall (MK) test and the Sen's slope (SS) at regional and NUTS3 level. The third stage used a principal component analysis (PCA) to assess potential relationships among trends in fire features at NUTS3 level.

Statistical analyses, plotting and mapping were carried out using the R statistical software (R Core Team, 2016), packages changepoint and trend for change point analysis, kendall and zyp for trend analysis and ggplot 2 for plotting and mapping the final results. 
(a)

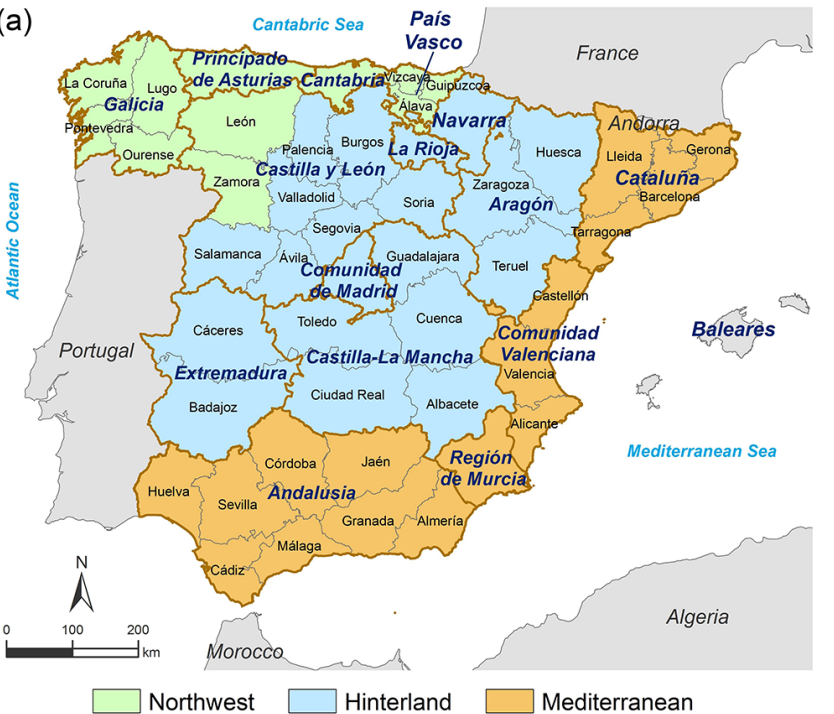

(b)

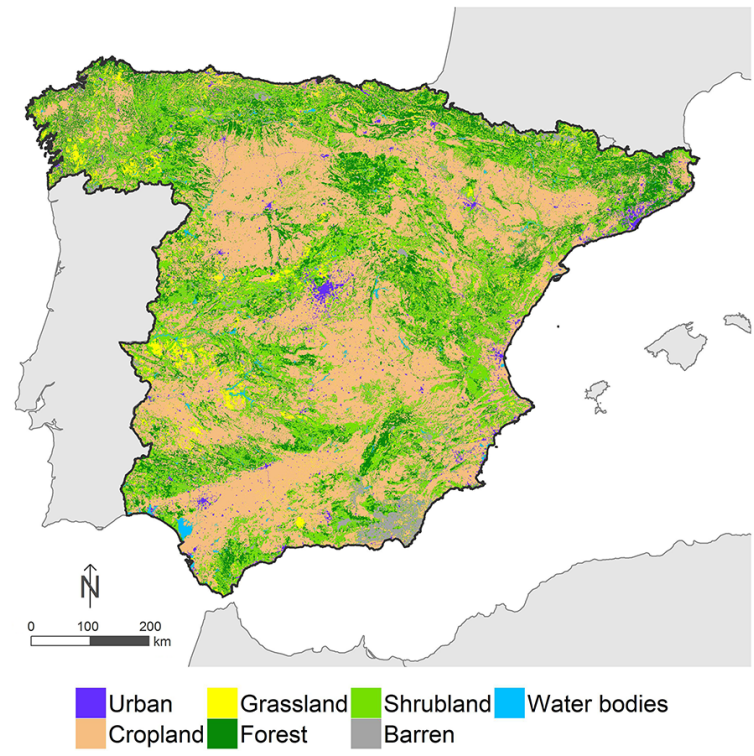

Figure 1. Spatial distribution of the three regions (Northwest, Hinterland and Mediterranean), NUTS3 and NUTS2 units in mainland Spain (a) and generalized land cover from CLC 2006 (b).

Table 1. Statistical summary of fire regime features 1974-2013. S: spring-summer; W: autumn-winter. In parentheses, the first value corresponds to inter-region percentage and the second value to intra-region percentage. Burned area data expressed in square kilometres.

\begin{tabular}{llrrrrrrrr}
\hline Region & Season & $\mathrm{N}$ & $\mathrm{N} 500$ & $\mathrm{NL}$ & $\mathrm{NH}$ & $\mathrm{B}$ & $\mathrm{B} 500$ & $\mathrm{BL}$ & $\mathrm{BH}$ \\
\hline & $\mathrm{S}$ & 100232 & 503 & 1445 & 69305 & 21864 & 4874 & 486 & 14568 \\
$\mathrm{NW}$ & & $(40)(60.4)$ & $(29.2)(79.1)$ & $(26.9)(96.5)$ & $(39.6)(57.4)$ & $(33.7)(69.3)$ & $(19.7)(79.3)$ & $(12.2)(98.6)$ & $(33.4)(65.6)$ \\
& $\mathrm{W}$ & 65826 & 133 & 53 & 51355 & 9708 & 1270 & 7 & 7627 \\
& & $(26.2)(39.6)$ & $(7.7)(20.9)$ & $(0.9)(3.5)$ & $(29.4)(42.6)$ & $(15)(30.7)$ & $(5.1)(20.7)$ & $(0.2)(1.4)$ & $(17.5)(34.4)$ \\
\hline & $\mathrm{S}$ & 35061 & 482 & 2593 & 21048 & 13307 & 6647 & 1771 & 7863 \\
HL & & $(13.9)(72.3)$ & $(27.9)(96.6)$ & $(48.2)(99.2)$ & $(12)(67.1)$ & $(20.5)(89.3)$ & $(27)(97.5)$ & $(44.6)(99.9)$ & $(18)(86.7)$ \\
& $\mathrm{W}$ & 13410 & 17 & 22 & 10329 & 1587 & 171 & 1 & 1207 \\
& & $(5.3)(27.7)$ & $(1)(3.4)$ & $(0.4)(0.8)$ & $(5.9)(32.9)$ & $(2.4)(10.7)$ & $(0.7)(2.5)$ & $(0)(0.1)$ & $(2.8)(13.3)$ \\
\hline & $\mathrm{S}$ & 28529 & 516 & 1230 & 17598 & 16146 & 10771 & 1685 & 10865 \\
MED & $\mathrm{W}$ & $(11.4)(78.5)$ & $(29.9)(87.5)$ & $(22.9)(97.2)$ & $(10.1)(77.1)$ & $(25)(87.9)$ & $(43.6)(91.7)$ & $(42.5)(98.9)$ & $(24.8)(87.6)$ \\
& & $(3.2)(21.5)$ & $(4.3)(12.5)$ & $(0.7)(2.8)$ & $(3)(22.9)$ & $(3.4)(12.1)$ & $(3.9)(8.3)$ & $(0.5)(1.1)$ & $(3.5)(12.4)$ \\
\hline Total & & 250878 & 1725 & 5379 & 174873 & 64827 & 24704 & 3969 & 43661 \\
\hline
\end{tabular}

\subsection{Change point detection}

Change detection or change point detection aimed to identify times when the probability distribution of a time series changes. In order to identify change points in our time series we used four different tests.

First we used the Pettitt test, a non-parametric method commonly applied to detect a single change-point in hydrological or climate series with continuous data (Pettitt, 1979). It tests the $\mathrm{H}_{0}$ (no change) against the alternative $\mathrm{H}_{1}$ (a change point exists). One of the advantages of this technique is its robustness to deal with outliers. In the context of wildfire science, the Pettitt test has previously been applied to detect fire regime shifts as a consequence of policy and socioeconomic development in Pezzatti et al. (2013) and Moreno et al. (2014).

The Pettitt test is calculated using the following equation:

$$
U t T=\sum_{i=1}^{t} \sum_{j=t+1}^{T} \operatorname{sgn}(X i-X j)
$$

where $\operatorname{sgn}(X)=1$ for $X>0,0$ for $X=0$ and -1 for $X<0$, and $T$ is the length of the time series in years. The probability of a significant change existing is calculated as follows:

$p(t)=1-\exp \left(\frac{-6 \cdot U_{t \cdot T}^{2}}{T^{3}+T^{2}}\right)$

where $\left|U_{t}, T\right|$ reaches the maximum value where the most significant change point is found (Pettitt, 1979). This 
methodology allows for the identification of the most probable change point in the period examined, in each fire feature by region and season. A specific function has been developed in $\mathrm{R}$ environment to calculate the change point using the Pettitt approach.

As an alternative method to the Pettitt test, three additional algorithms were applied; more specifically, the cpt.meanvar method to identify changes in mean and variance, calculating the optimal positioning of a change point for the input data (Chen and Gupta, 2000):

- AMOC (at most one change) method is the simplest expression of the change detection algorithms from the changepoint package. It can detect a single change point (Hinkley, 1970), much the same as the Pettitt test.

- PELT (pruned exact linear time) is one of the most widely used methods for change point detection. It can detect multiple change points in large data sets (Killick et al., 2012), unlike the Pettitt test or AMOC. It includes an enhanced optimal partitioning, leading to a substantially more accurate segmentation. This ensures minimum change point detection in a time series, regardless of the applied penalty value. Thus, PELT is known as a more precise algorithm, usually outperforming other methods such as binary segmentation. The CROPS (changepoints for a range of penalties) penalizing type was selected. The lower the pen.value is, the higher the numbers of change points detected. For this reason, we chose many different minimum pen.values, in order to find at least one, or no more than two, breakpoints. One of the advantages of this last option is that continuous false change points were avoided commonly found at the beginning/end of the time series (for example, many cases with AMOC algorithm).

- BinSeg (binary segmentation) is an effective method for multiple change point detection (Scott and Knott, 1974). It searches for the first significant change point in a sequence, then breaks the original sequence into two subsequences: before and after the first significant change point. The procedure tests the two sub-sequences separately for a change point, with the process repeated until no further sub-sequences have change points (Chen and Wang, 2009). In our case, we previously defined a possible change point limited in $1(Q=1)$, to obtain only the most significant. To this end, the default penalty parameter MBIC (modified Bayes information criterion penalty) was chosen, which has proved to reduce overestimation in the number of change points and often detects the correct model (Bogdan et al., 2008). Therefore, there is no need to select a penalty value; hence in all the cases, this value is automatically established as 14.8 .

\subsection{Trend analysis}

Change detection procedures determine if and when a certain feature has undergone a significant change across the study period. However, does it imply an increase or decrease in the values of that feature? Moreover, how strong is that change? Is the change stationary or does it vary over space? To answer all these questions, we used a trend detection procedure combining the MK and SS.

MK is a non-parametric statistical test appropriate for identifying trends in time series of data (Kendall, 1975; Mann, 1945). It is suitable for detecting linear or non-linear trends (Hisdal et al., 2001; Wu et al., 2008). In this test, the null $\left(\mathrm{H}_{0}\right)$ and alternative hypotheses $\left(\mathrm{H}_{1}\right)$ are equal to the non-existence and existence of a trend in the time series of the observational data, respectively. Previous studies by SanMiguel-Ayanz et al. (2012) and Rodrigues et al. (2013) support the use of MK in the context of wildfire science. MK main outputs are the $\tau$ value and its associated significance level ( $p$ value). $\tau$ can be used to determine the sign of the trend, i.e. upward $(\tau>0)$ or downward $(\tau<0)$. Trends are considered significant when $p$ value $<0.05$. To facilitate the interpretation of MK outcomes, we calculated an aggregated parameter combining the $\tau$ and $p$ value, the so-called "signed $p$ value". It combines information on both sign and significance, calculated as the multiplication of the significance level either by 1 when $\tau>0$ or by -1 when $\tau<0$.

The magnitude of the change was subsequently assessed by means of the SS (Sen, 1968), a non-parametric alternative for estimating the median slope joining all possible pairs of observations, which enables a comparison of the magnitude of the detected trends. Both MK and SS were calculated for all fire features by region and NUTS3 level and for both seasons.

\subsection{Principal component analysis and mapping}

Finally, PCA was carried out on Sen's slope's values in order to synthesize the detected changes. PCA is a widely used technique for summarizing a large set of variables into fewer and common factors, reducing the variance of the original data. Representative principal components (PCs) were selected using the Kaiser criterion (Kaiser, 1960), which only retains PCs with eigenvalues greater than 1 . In turn, the varimax rotation (VR) method was applied to identify key trends. VR transforms the selected PC, maximizing the sum of the variance and thus obtaining higher coefficients or near to zero with fewer intermediate values. The objective is to link each variable to one maximum PC to make interpretation of PCA results easier (Horst, 1965; Kaiser, 1958).

Furthermore, we summarized the temporal behaviour retrieved from PCs on an additional map. Eigenvalues from PCs 1 and 2 were classified into four categories according to their sign (positive or negative trends) and significance level (above (significant) or below (non-significant)) a $90 \%$ con- 
Table 2. Change points for AMOC (at most one change), BinSeg (binary segmentation), PELT (pruned exact linear time) methods and Pettitt test $(*$ significant changes $p$ value $<0.05)$ by fire feature, region and season from the period 1974-2013. Bold features indicate matching probable changes in at least three methods. NW is Northwest, HL is Hinterland and MED is the Mediterranean. See Sect. 2.1 for acronyms and description of fire features.

\begin{tabular}{|c|c|c|c|c|c|c|c|c|c|c|c|c|}
\hline & \multicolumn{4}{|c|}{ NW } & \multicolumn{4}{|c|}{$\mathrm{HL}$} & \multicolumn{4}{|c|}{ MED } \\
\hline & \multicolumn{4}{|c|}{ Summer } & \multicolumn{4}{|c|}{ Summer } & \multicolumn{4}{|c|}{ Summer } \\
\hline & AMOC & BinSeg & PELT & Pettitt & AMOC & BinSeg & PELT & Pettitt & AMOC & BinSeg & PELT & Pettitt \\
\hline $\mathrm{N}$ & - & 2006 & 2000,2006 & 2005 & - & 1977 & 1977 & 1983 & 1994 & 1994 & 1994 & 1994* \\
\hline B & - & 1990 & 1990 & 1991* & - & 1977 & 1977 & 1991 & - & 1994 & 1994 & $1994^{*}$ \\
\hline N500 & - & 2006 & 2006, 2008 & 1990 & - & 1991 & $1981,1983,1991$ & 1991 & 1994 & 1994 & 1995,1997 & $1994^{*}$ \\
\hline B500 & - & 2006 & 2006, 2008, 2010 & 1991 & - & 1977 & 1977 & 1991 & - & 1994 & 1992,1994 & 1994* \\
\hline NL & - & 2006 & 1982,1984 & $1988^{*}$ & - & 2006 & 1980,2006 & 1980 & 2011 & 1994 & 2011 & 1996 \\
\hline $\mathrm{BL}$ & - & 2006 & 2006,2010 & 1988 & - & 1990 & 1990 & 1995 & 1995 & 1994 & 1994 & 1994 \\
\hline $\mathrm{NH}$ & - & 1976 & 2000,2006 & 2006 & - & 1977 & 1977 & $1997^{*}$ & - & 2005 & 1991, 1993 & $1994^{*}$ \\
\hline \multirow[t]{3}{*}{$\mathrm{BH}$} & - & 2008 & 2008 & 1990 & - & 1977 & 1977 & 1977 & - & 1994 & 1990,1994 & $1994^{*}$ \\
\hline & \multicolumn{4}{|c|}{ Winter } & \multicolumn{4}{|c|}{ Winter } & \multicolumn{4}{|c|}{ Winter } \\
\hline & AMOC & BinSeg & PELT & Pettitt & AMOC & BinSeg & PELT & Pettitt & AMOC & BinSeg & PELT & Pettitt \\
\hline $\mathrm{N}$ & - & 1984 & 1984 & $1987^{*}$ & - & 1987 & 1987 & $1987^{*}$ & - & 2005 & 1995,1997 & 1999 \\
\hline B & - & 1984 & 1984,1989 & $1987^{*}$ & - & 1989 & 1989 & 2000 & 1985 & 1985 & 1985 & $1986^{*}$ \\
\hline N500 & - & 1989 & 1990, 1993, 1995 & 1996 & - & 1977 & 1995, 2009 & 1989 & 1984 & 1984 & 1992,1999 & $1986 *$ \\
\hline B500 & - & 1984 & 1990,1993 & 1996 & - & 1977 & 1995, 2009 & 1989 & 1984 & 1984 & 1992,1999 & $1986^{*}$ \\
\hline NL & 1994 & 1993 & 2000,2007 & 1993 & - & 1976 & 1976 & 1990 & - & 1977 & 1977 & 1992 \\
\hline $\mathrm{BL}$ & - & 1984 & 2002,2007 & 1993 & 1990 & 1989 & 1990,1994 & 1990 & - & 1977 & 1977 & 1999 \\
\hline $\mathrm{NH}$ & 1987 & 1987 & 1987 & $1987^{*}$ & - & 1987 & 1987 & $1987^{*}$ & - & 2005 & 2005 & 2005 \\
\hline $\mathrm{BH}$ & - & 1984 & 1984 & $1987^{*}$ & - & 1989 & 1989 & 1987 & 1981 & 1981 & 1981 & $1986^{*}$ \\
\hline
\end{tabular}

fidence interval. PCs 3 and 4 were only shown when significant. In this way, we were able to outline homogeneous areas according to the observed temporal evolution.

\section{Results}

\subsection{Change point detection}

Only those cases where at least three of the methods agree in the year of change are taken as change points. Table 2 summarizes the year(s) of change obtained by the four algorithms. The majority of change points were detected between the late 1980s and the early 1990s. Change points have been detected in the MED region in N S, B, N500, B500, BL S, $\mathrm{NH} \mathrm{S}$ and $\mathrm{BH}$. Summer changes are consistently observed in 1994 in the MED features, whereas changes in the winter season in this region appear around in 1984-1986. Additionally, another six change points were found in the NW region in NH W in 1987, NL W in 1993 and B S in 1991 and two in N W and B W were found in 1984-1987. Finally, one change point was detected in N S, but in 2005-2006. In HL, five change points were found in N W and $\mathrm{NH} \mathrm{W}$ in 1987, N500 S and BL W in 1990-1991 and finally BH S in 1977. It is important to note that some fire features in particular regions are very few, such as in HL and NW regions, which do not appear in Figs. 2 and 3.

\subsection{Trends analysis}

\subsubsection{Region level}

Table 3 summarizes the results from MK. Similar to change point analysis, the MED region stands out as the one with most significant changes. In general, the region returns mostly downward trends in all fire features, significant in all cases and seasons, except NL, NH and BH during winter. Only a few features underwent a trend either way in the NW region. Significant upward trends were detected in N, $\mathrm{B}, \mathrm{NH}$ and $\mathrm{BH}$. In all cases, trends occurred during the winter season. Significant downward trends were found in B and B500 during summer. Again, HL is the region with fewest significant trends. Overall, human-related features $(\mathrm{NH}$ and $\mathrm{BH}$ ) show significant upward trends in summer and winter, whereas $\mathrm{N}$ increases during winter.

\subsubsection{NUTS3 level}

Trend detection analysis at NUTS3/provincial level combines MK and SS values. Maps in Fig. 4 summarize the results of this section. Every single map displays the results for a given fire feature. The overall value of the feature, i.e. total number of fires, burnt area and number of human-caused fires, is represented by symbol (circle) size. The colour of the circle indicates whether the MK test denotes a significant trend or not. Grey circles represent non-significant trends, whereas coloured symbols denote significant trends. For the 


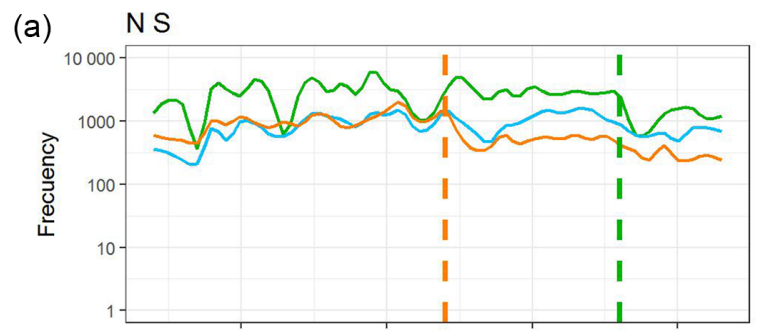

(b)
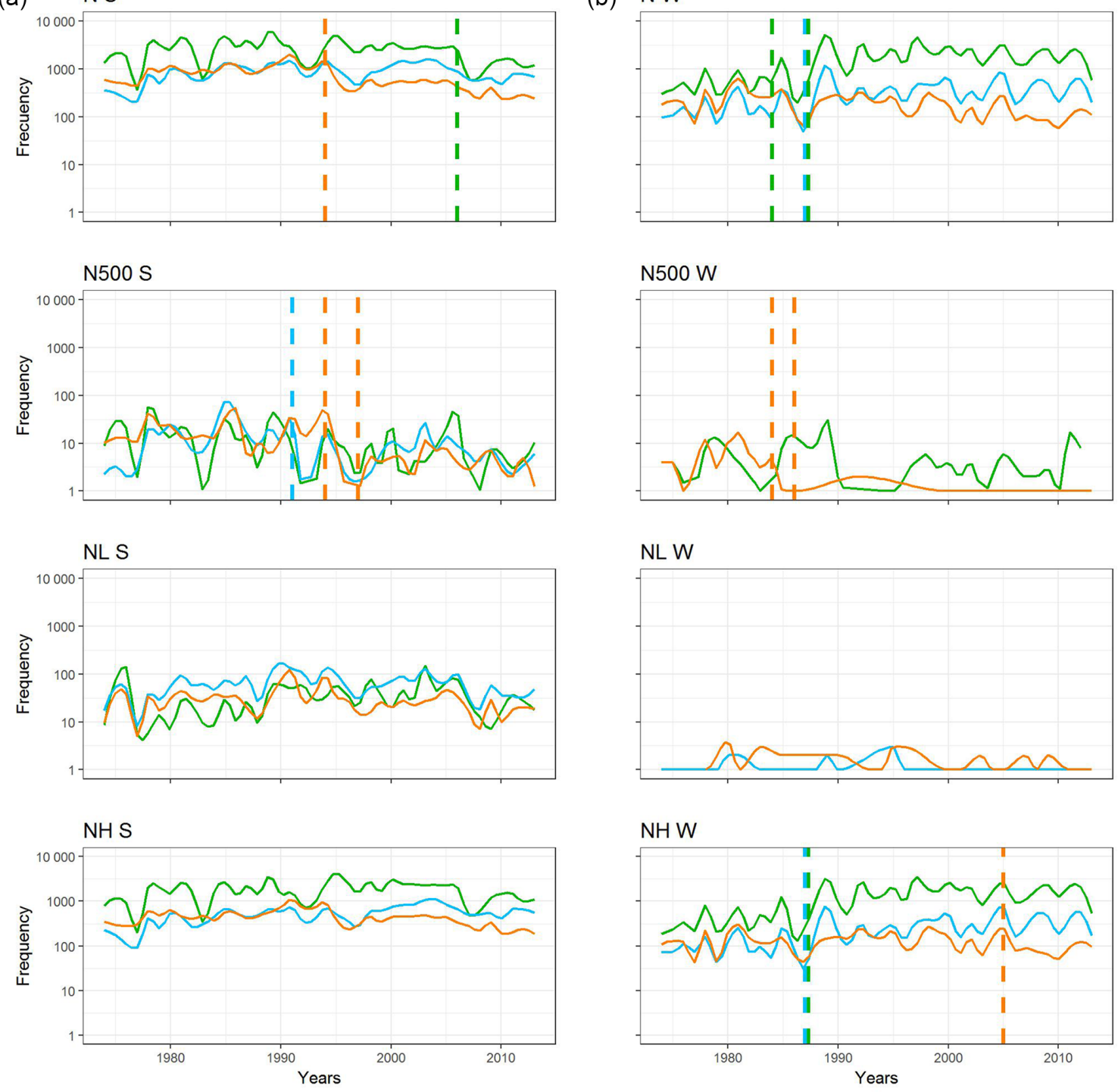

Figure 2. Detected change points and temporal evolution of fire frequency features (log scale) for the period 1974-2013 in the three regions examined: Northwest is indicated by the green line, Hinterland by the light blue line and the Mediterranean by the orange line. Column (a) refers to the summer season, while (b) is winter. Dashed vertical lines represent probable change points. See Sect. 2.1 for acronyms and description of fire features.

significant trends, the value of the SS is plotted inside the circle. We used a gree-yellow-red colour ramp to represent both the sign of the trend (negative in green and positive in red) and the trend magnitude according to the SS value.

Observing the spatial distribution of significant trends, an increment in $\mathrm{N}$ was found in provinces of the northwestern area and the western provinces of the hinterland on the border with Portugal. Similar to the results at regional level, provinces on the Mediterranean coast show a decrease in the number of fires, although some provinces in the southern region (Andalusia) do not show significant trends. However, differences in the seasonal behaviour were observed, with increasing trends found in the eastern provinces in NW.
In turn, provinces with significant decreasing trends were located along the Mediterranean coast, southern Andalusia and the majority of provinces in Galicia. Winter N clearly presents an increase for most of the NW region and many areas of the HL.

This spatial distribution changes slightly for total B and summer B compared to those observed in $\mathrm{N}$, being more visible in the northwestern area (Galicia and Asturias) and large part of Andalusia, where negative trends play a decisive role at the expense of positive trends. However, NH shows more increases across the territory, except the Mediterranean coast. However, with $\mathrm{BH}$, decreases are more evident, mainly con- 
(a)

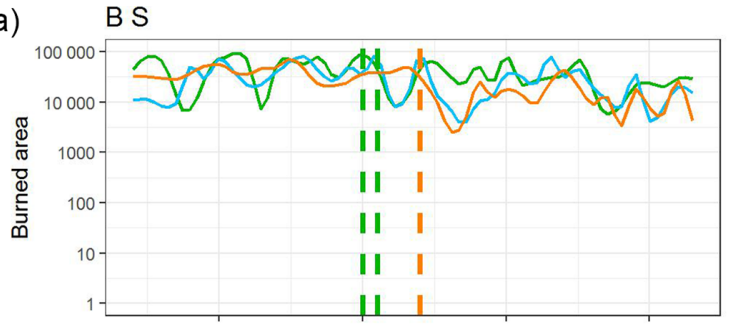

\section{B500 S}

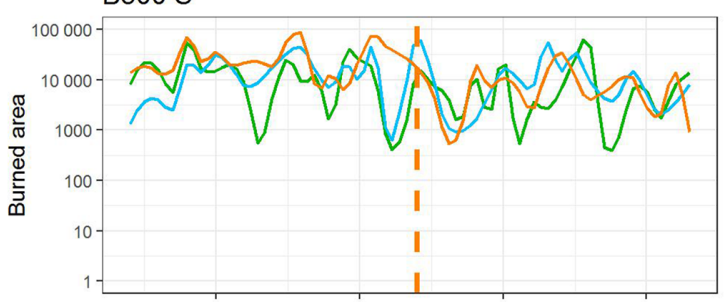

BL S
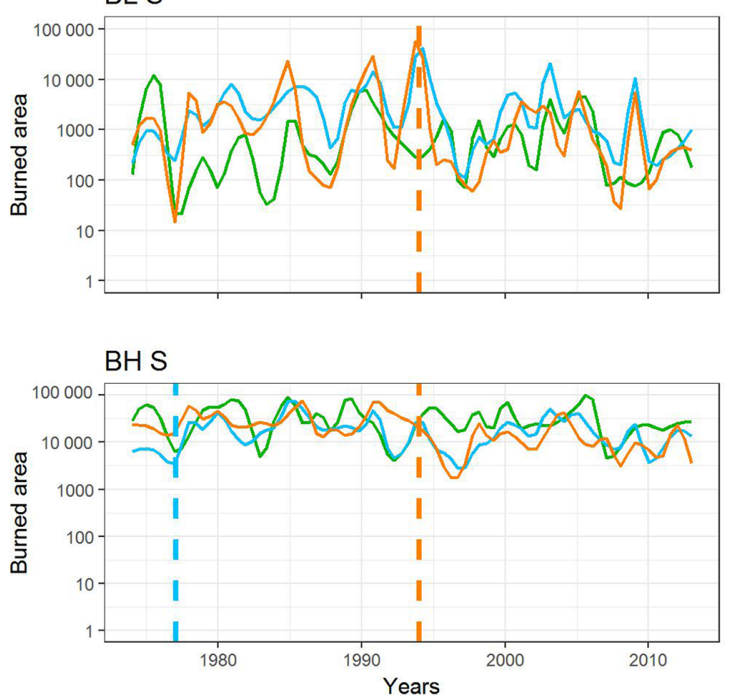

(b)

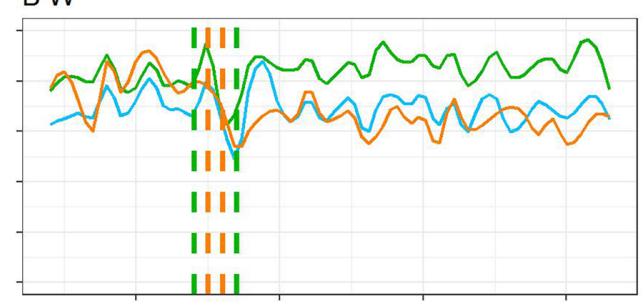

B500 W

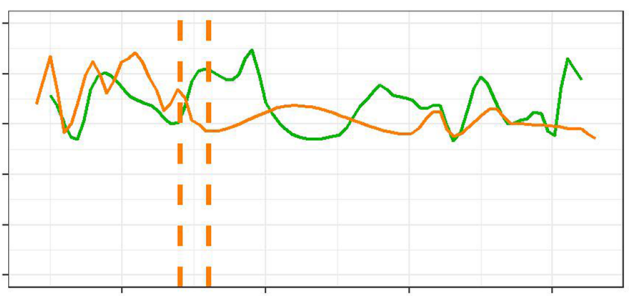

BL W

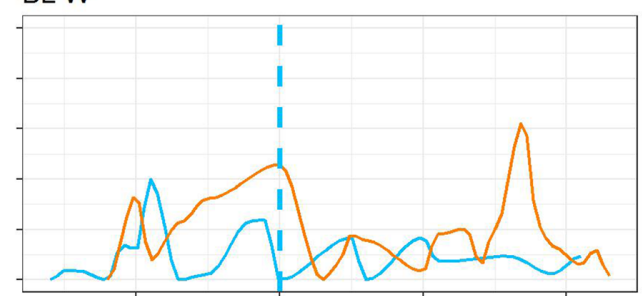

BH W

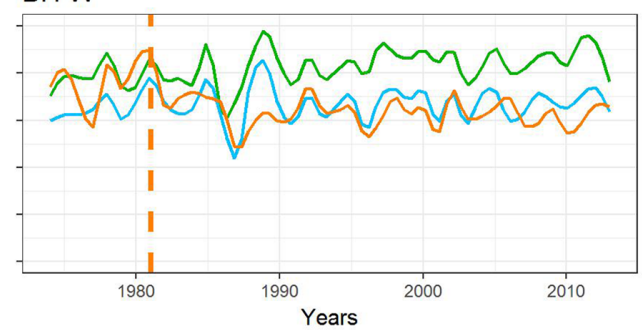

Figure 3. Detected change points and temporal evolution of burned area features (log scale) for the period 1974-2013 in the three regions examined: Northwest is indicated by the green line, Hinterland by the light blue line and the Mediterranean by the orange line. Column (a) refers to the summer season, while (b) is winter. Dashed vertical lines represent probable change points. See Sect. 2.1 for acronyms and description of fire features.

centrated in the northeast coastal areas, some provinces of the northwest and Andalusia.

The spatial distribution of SS values across mainland Spain reveals a high spatial variability in trend magnitude. The strongest trends according their standard deviation $(\mathrm{SD}<-1.64)$ or $(\mathrm{SD}>1.64)$ were found in the NW area, both positive and negative. Strong positive trends were identified in winter fire features relating to frequency, such as total $\mathrm{N}$ and $\mathrm{N}-\mathrm{NH}$, but also with burned areas, as with $\mathrm{B}$ and $\mathrm{BH}$. In contrast, the main negative trends were located again in the NW region for some summer fire features like N, B, $\mathrm{NH}$ and $\mathrm{BH}$. In addition, the rest of the territory is covered by intermediate values, mainly in total $\mathrm{N}$ and $\mathrm{B}, \mathrm{B} \mathrm{S}, \mathrm{N} \mathrm{W}$ and
$\mathrm{NH}$. However, in most areas moderate negative trends play a major role (especially in the Mediterranean coast) whereas moderate positive dynamics are concentrated in the western provinces of hinterland.

\subsection{Principal component analysis and varimax rotation}

PCA was applied to SS values. Results from PCA provide an overview of the most relevant links among trends in fire features. According to the Kaiser criterion, 4 components (representing $88 \%$ of the variance) out of the initial 14 were selected. Consequently, VR was only calculated for those four PCs. According to PCA eigenvalues (Table 4), PC1 (38\% 
$\mathbf{N}$

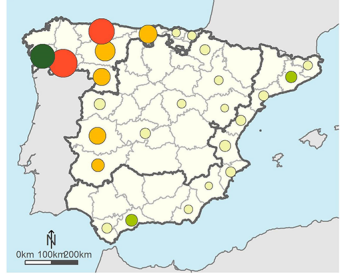

N W

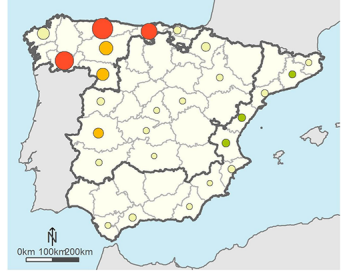

NH S

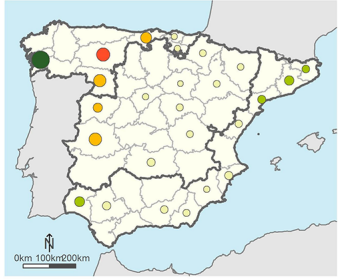

N S

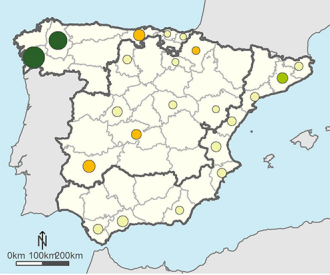

N500 S

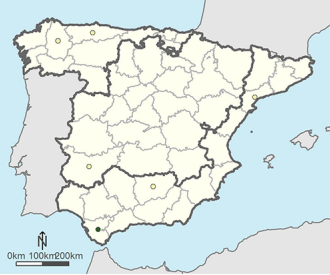

NH W

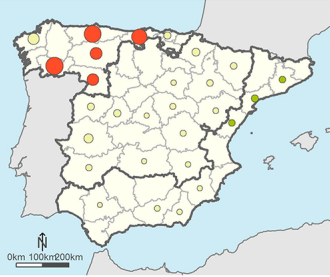

NLS

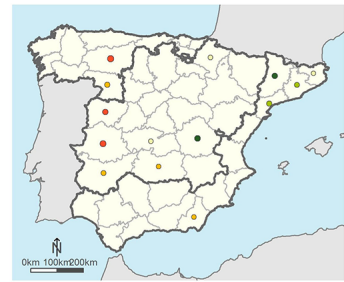

Number of wildfires $\quad 100$
B

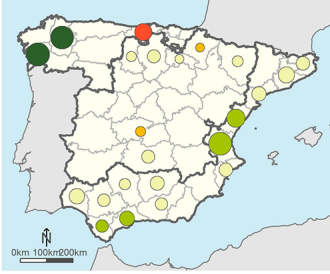

B W

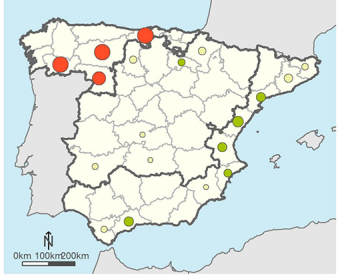

BH S

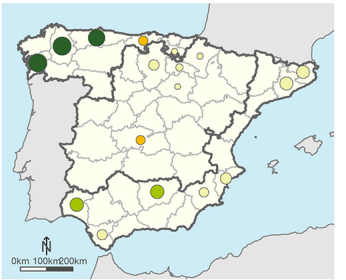

BL S

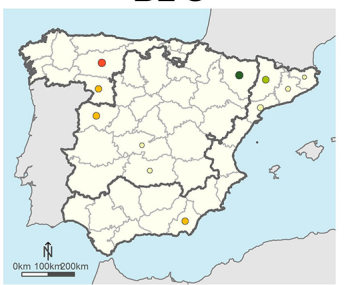

$1000 \bigcirc 10000 \bigcirc 34246$

Burned area (ha) 1000

$10000 \bigcirc 100000 \bigcirc 581520$

Sen's Slope

Decrease Small decrease

Stable Small increase

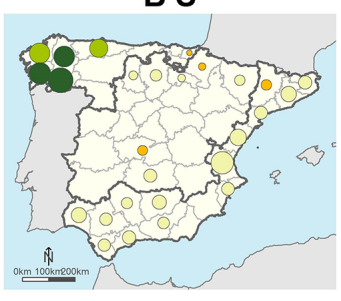

B500 S

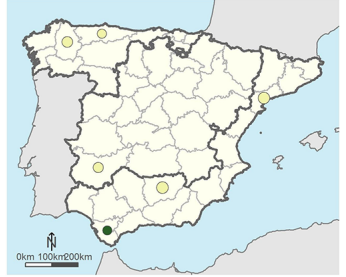

BH W

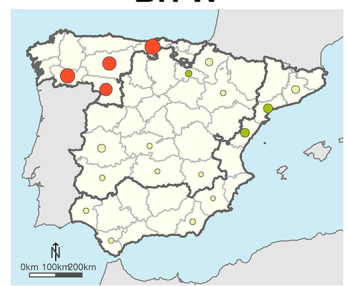

B S

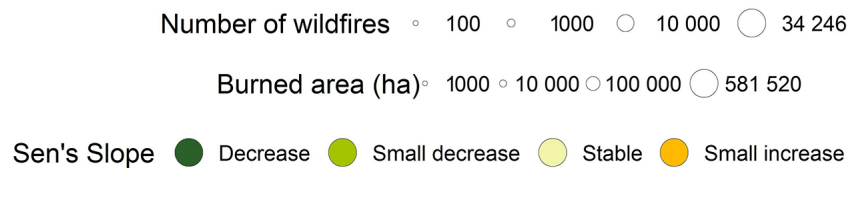

Figure 4. Spatial distribution of selected significant Sen's slope (SS) values from 1974 to -2013 according to Mann-Kendall. SS classes are based on the following intervals: decrease $(<-1.6)$, small decrease $(-1.6 ;-0.5)$, stable $(-0.5 ; 0.5)$, small increase $(0.5 ; 1.6)$ and increase (>1.6). Proportional symbols represent the number of wildfires and burned area value. SS value is displayed in colour using standard deviation intervals. Provinces without symbols represent non-significant trends according Mann-Kendall test. See Sect. 2.1 for acronyms and description of fire features.

of the variance) is associated with changes in fire frequency, particularly the number of fires and human-caused fires during winter. PC1 gathers $\mathrm{N}(0.44), \mathrm{N} \mathrm{W}(0.52)$ and $\mathrm{NH} \mathrm{W}$ (0.45). PC2 (27\% of the variance) relates to the fire-affected area. B (0.47), B S (0.44), BH S (0.44) and N S (0.43), suggest that burned area trends are mainly related to summer human dynamics and a slight increase in summer fire frequency. Large fire trends are noticeably isolated in PC3 (15\% of the variance in terms of both frequency and burned area). Finally, PC4 (8\% of the variance) separates natural fires dynamics in the same way as large ones fall into PC3. In general, PC1 relates to winter fire frequency, PC2 to summer burnt area, PC3 to large fires and PC4 to natural fires.

Figure 5 displays PC values at NUTS3 level. The NW and, to a lesser extent, MED regions show the highest magnitude of change when looking at the four PCs in the same picture. PC1 displays both the highest and lowest values in the NW region, although some provinces in the northeast area of the Mediterranean also show low values. PC2 shows higher values over the HL region and lower in the western area of NW. Lower values were observed for PC3 in some provinces of the Ebro Valley and others, such as Va- 
lencia, Cádiz and Ourense. In contrast, some provinces in the western NW show moderately increased values (especially in León). However, PC4, which represents naturally caused fires, exhibits intermediate positive values all over the study region, especially some provinces in the hinterland of the NW region, Valencia and Cádiz. Finally, the main negative values are located in several provinces on the Cantabrian (north) coast and the central Pyrenees (Huesca).

Figure 6 displays the summary of PCA. Increased fire frequency was observed only in the NW region, in the inland provinces of León, Zamora and Ourense, as well as in the Cantabrian cornice. Nevertheless, the burnt area decreased throughout the region. A significant winter frequency decrease was solely found in Pontevedra. However, a nonsignificant winter frequency decrease was observed along the Mediterranean coast and most of the interior of the country. In these latter areas, an increased summer burnt area was also observed. In contrast, a significant decrease in the summer burnt area was only detected in the Galician provinces (NW). In addition, significant trends in large or natural fires were found in the three regions. Increased lightning fire activity was observed in León and Zamora (NW) and Valencia (MED). Lesser natural fire activity was detected in Asturias (NW) and Huesca (HL). In turn, the occurrence of large fires was more frequent in León and Pontevedra (NW), whereas the opposite could be found in Ourense (NW), Huesca (HL) and Valencia (MED).

\section{Discussion}

In this paper, we present an analysis of spatial-temporal trends of several fire regime features at different scales for mainland Spain. Various statistical methods for time series were applied to historical fire data to (i) explore the temporal behaviour of fire features and (ii) investigate key relationships in trends, with the end purpose of the research being to improve the definition of fire regime. It should be noted that the analysis is based on historical fire records, and thus there are some limitations related to landscape-level fuel build-up that cannot be addressed.

Change detection procedures suggest the existence of change points in several fire features (Table 2). Changes were mostly found in the Mediterranean region from the late 1980s to the first half of the 1990s. Moreno et al. (2014) support our findings for number of fires and burned area on a seasonal scale, and they also found similar change points using the Pettitt test on a stepwise approach with an 11-year moving window. This work is a particularly good match for our objective because the same regions and fire data from the EGIF database were used, although the study period was slightly different (1968-2010) and only examined number of fires and burnt area. In particular, these authors observed downward changes starting from the 1990s to the present in the Mediterranean region for both winter and summer and in the summer of Northwest and Hinterland, which are in line with our findings (see Fig. 2). They concluded that climate might have played a role in the change points of the Mediterranean region (mid-1980s and 1990s) and the Northwest region (1991). In addition, the change points we detected in the Northwest region for the number of winter fires (Fig. 2) might be linked to different causes, such as rising population density, agricultural activities and more cases of arson, as Moreno et al. (2014) have pointed out. However, increased investment in fire suppression might have played a role in reducing the burned area (Seijo and Gray, 2012). However, this is a difficult aspect; in this sense the analysis in the northern region of Portugal (Fernandes et al., 2014) found that the shift towards decreasing area burned did not happen in areas with unsuccessful/insufficient fire-fighting efforts.

Overall, all methods detect significant changes in some fire features in the Mediterranean and the Northwest regions during both seasons, although slight differences in the reported year do exist.

We considered it necessary to assess other fire regime features, such as large fires and fire sources. The inclusion of trends in large fires is justified because of their remarkable socioeconomic and natural impact (Alvarado et al., 1998; San-Miguel-Ayanz et al., 2013). Change detection suggests that the number of large fires has changed since the mid1990s throughout the Mediterranean (see Fig. 2), supported by findings from MK, which detects a decrease in frequency and affected area (Table 3). Cardil and Molina (2013) report similar changes, although these authors have taken large fires to be those burning more than 100 ha and have excluded some provinces from their assessment. They and others, like Brotons et al. (2013) and Ruffault and Mouillot (2015), suggest that large fires have decreased because extinguishing methods have improved, again, mainly due to the extraordinary investment that Spain has devoted to fire suppression.

Findings from change detection are supported and completed by those from trend analysis. At a regional level, the Mediterranean region shows a negative trend in the majority of fire features (see Table 3). The Northwest and Hinterland share a positive trend during winter. Number of fires presents a general downward trend in both seasons in the Mediterranean and during summer in Northwest. In the case of the Hinterland region, the trend in the number of fires suggests a higher frequency in winter. This behaviour was also found by Zavala et al. (2011) and Turco et al. (2016). The latter found an apparent shift in the mid-1980s, the same as we detected. Among the feasible causes that may explain this spatial contrast, we found factors such as land use changes caused by land abandonment leading to vegetation recovery during recent years (Bonet and Pausas, 2007; Castellnou et al., 2010), resulting in an accumulation of fuels. However, the burned area shows a decrease in all regions and seasons. Previous studies by Rodrigues et al. (2013), Spano et al. (2014) and Turco et al. (2016) have also found negative trends for a very similar time span. These works sug- 

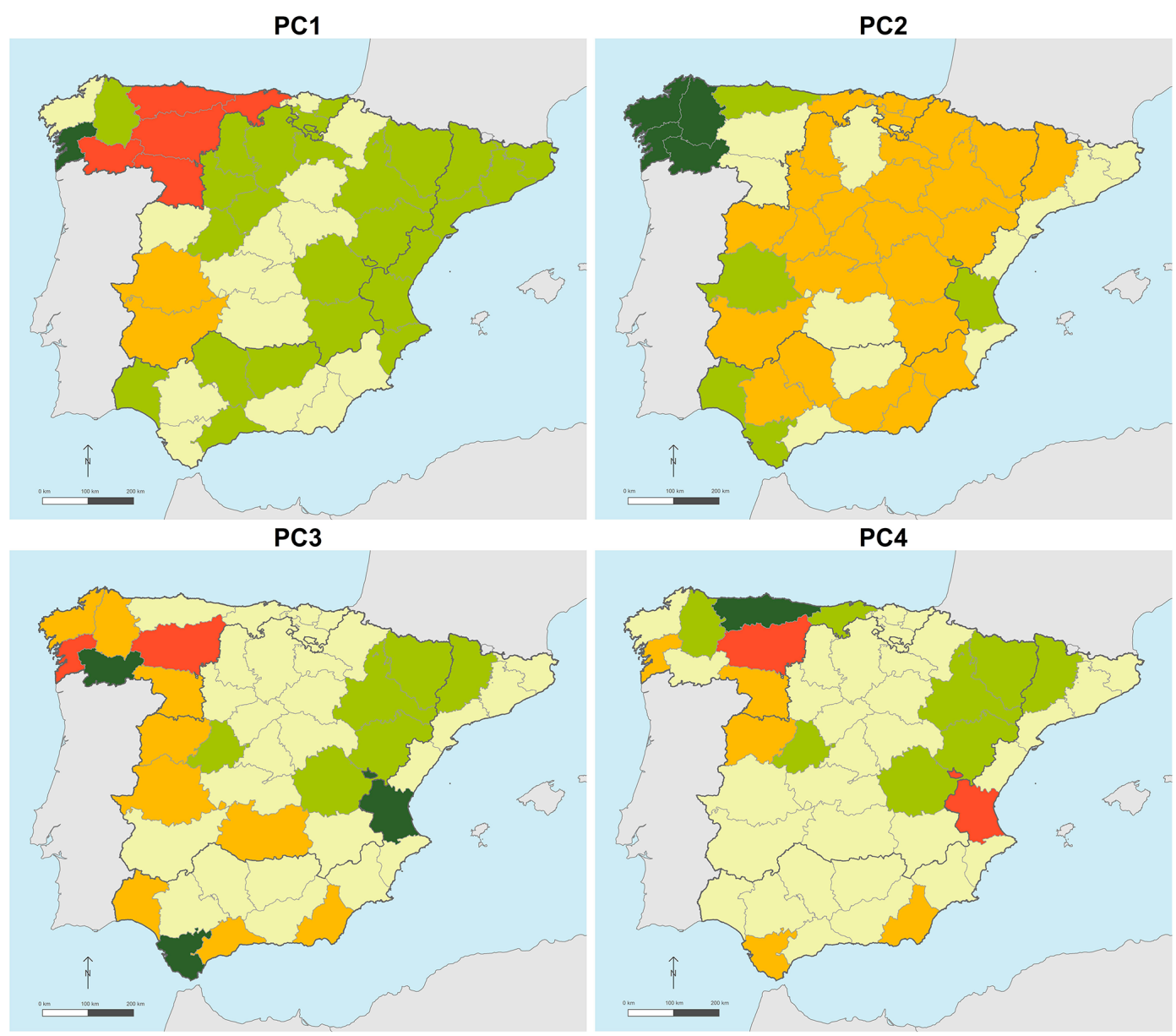

Sen's slope value (SD) $\square$ Decrease $\square$ Small decrease $\square$ Stable $\quad$ Small increase $\square$ Increase

Figure 5. Spatial distribution of the principal component coefficients of Sen's slope, 1974-2013. Values represented using standard deviation intervals. Sen's slope classes are based on the following intervals: decrease $(<-2.5)$, small decrease $(-2.5 ;-0.5)$, stable $(-0.5 ; 0.5)$, small increase $(0.5 ; 2.5)$ and increase $(>2.5)$.

Table 3. Signed $p$ value of Mann-Kendall test in the period 1974-2013 by fire feature, season and region. Values in bold correspond to significant trends ( $p$ value $<0.05$ ), with their corresponding symbol + or - for positive or negative trends, respectively. NW is the Northwest; $\mathrm{HL}$ is the Hinterland; MED is the Mediterranean region. See Sect. 2.1 for acronyms and description of fire features.

\begin{tabular}{|c|c|c|c|c|c|c|c|c|}
\hline & \multicolumn{2}{|c|}{$\mathrm{N}$} & \multicolumn{2}{|c|}{ N500 } & \multicolumn{2}{|c|}{ NL } & \multicolumn{2}{|c|}{$\mathrm{NH}$} \\
\hline & $\mathrm{S}$ & W & $\mathrm{S}$ & W & $\mathrm{S}$ & W & $\mathrm{S}$ & W \\
\hline NW & $-(0.14)$ & $+(\mathbf{0 . 0 1})$ & $-(\mathbf{0 . 0 3})$ & $+(0.26)$ & $+(0.14)$ & $-(0.49)$ & $+(0.77)$ & $+(\mathbf{0 . 0 1})$ \\
\hline $\mathrm{HL}$ & $+(0.21)$ & $+(\mathbf{0 . 0 1})$ & $-(0.22)$ & $-(0.39)$ & $+(0.62)$ & $-(\mathbf{0 . 0 3})$ & $+(\mathbf{0 . 0 1})$ & $+(\mathbf{0 . 0 1})$ \\
\hline \multirow[t]{3}{*}{ MED } & $-(\mathbf{0 . 0 1})$ & $-(\mathbf{0 . 0 1})$ & $-(\mathbf{0 . 0 1})$ & $-(0.01)$ & $-(0.11)$ & $+(0.13)$ & $-(\mathbf{0 . 0 1})$ & $-(0.54)$ \\
\hline & \multicolumn{2}{|c|}{ B } & \multicolumn{2}{|c|}{ B500 } & \multicolumn{2}{|c|}{ BL } & \multicolumn{2}{|c|}{$\mathrm{BH}$} \\
\hline & S & W & S & W & S & W & S & W \\
\hline NW & $-(\mathbf{0 . 0 1})$ & $+(\mathbf{0 . 0 3})$ & $-(0.13)$ & $+(0.41)$ & $+(0.68)$ & $-(0.28)$ & $-(0.13)$ & $+(\mathbf{0 . 0 1})$ \\
\hline HL & $-(0.25)$ & $-(0.95)$ & $+(0.51)$ & $-(0.48)$ & $-(0.44)$ & $-(0.08)$ & $+(0.84)$ & $+(0.84)$ \\
\hline MED & $-(\mathbf{0 . 0 1})$ & $-(0.01)$ & $-(0.01)$ & $-(0.01)$ & $-(0.22)$ & $+(0.06)$ & $-(0.01)$ & $+(\mathbf{0 . 0 1})$ \\
\hline
\end{tabular}




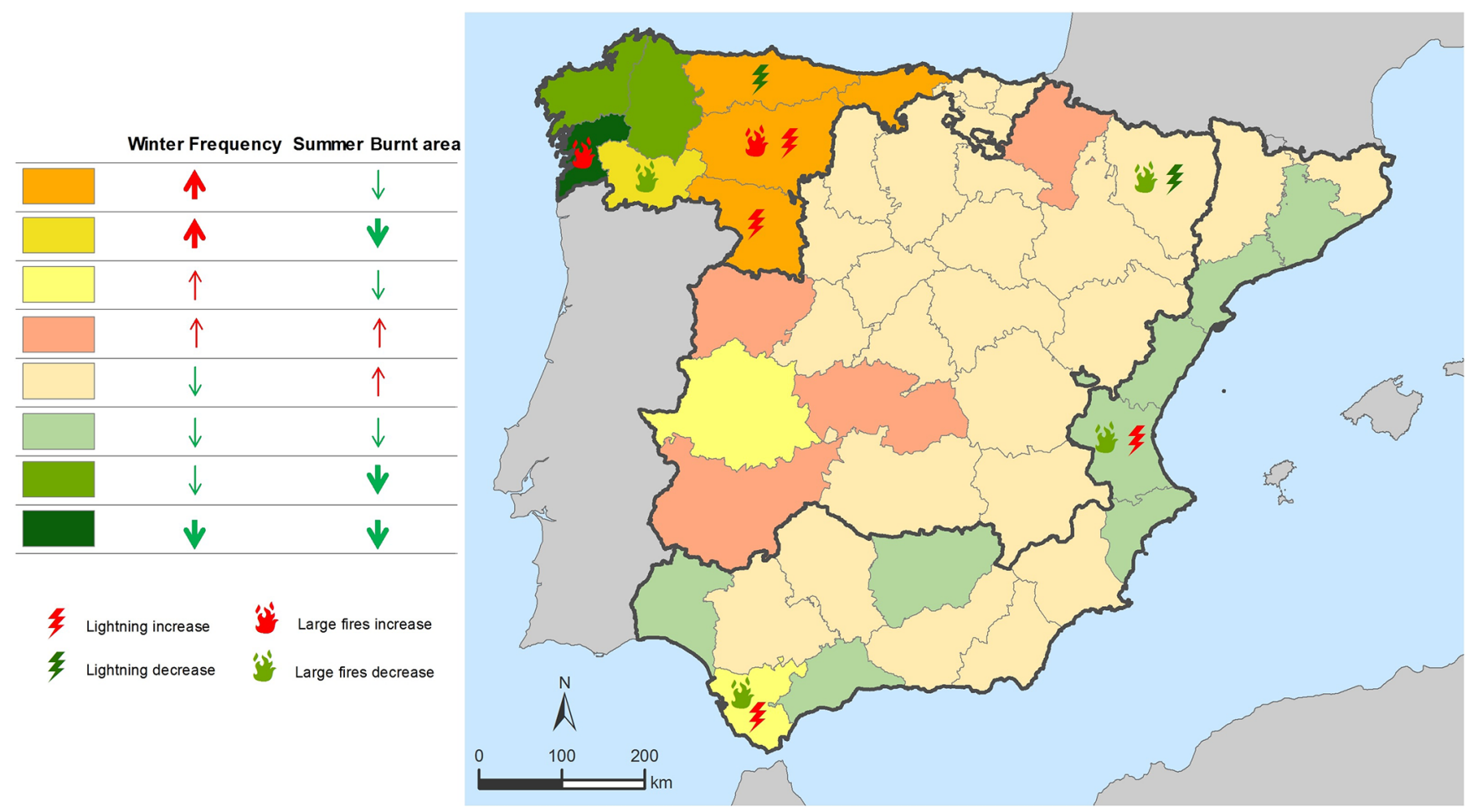

Figure 6. Summary of spatial-temporal behaviour from principal component analysis. Thick arrows mean significant trends, and thin ones are non-significant trends according to $90 \%$ confidence interval.

Table 4. Varimax rotation correlation values, standard deviation (SD) and variance (VAR) from principal component analysis on Sen's slope results, 1974-2013. The most meaningful features (correlation $>0.43$ or $<-0.43$ ) are marked bold. See Sect. 2.1 for acronyms and description of fire features.

\begin{tabular}{llrrrr}
\hline & & PC1 & PC2 & PC3 & PC4 \\
SD & & 2.3 & 1.95 & 1.47 & 1.07 \\
VAR & & 0.38 & 0.27 & 0.15 & 0.08 \\
\hline Fire & N & $\mathbf{0 . 4 4}$ & 0.23 & & -0.14 \\
feature & N S & 0.18 & $\mathbf{0 . 4 3}$ & & -0.11 \\
& N W & $\mathbf{0 . 5 2}$ & 0.11 & -0.10 & \\
& B & & $\mathbf{0 . 4 7}$ & & \\
B S & -0.18 & $\mathbf{0 . 4 4}$ & 0.11 & \\
B W & 0.35 & & & 0.21 \\
N500 S & & & $\mathbf{0 . 6 3}$ & \\
B500 S & & & $\mathbf{0 . 6 9}$ & \\
NL S & & & & $\mathbf{0 . 6 0}$ \\
BL S & & & & $\mathbf{0 . 6 0}$ \\
NH S & 0.19 & 0.36 & -0.17 & 0.12 \\
NH W & $\mathbf{0 . 4 5}$ & & & \\
BH S & -0.20 & $\mathbf{0 . 4 4}$ & -0.14 & 0.27 \\
BH W & 0.27 & & -0.14 & 0.29 \\
\hline
\end{tabular}

gest that the decrease might be explained by recent improvements in management of wildfires and monitoring systems. Additionally, the European Forest Fire Information System
(EFFIS) observed a clear downward trend in the total burnt area in some southern European countries (including Spain) after 1990, partly due to improved fire protection services (Schmuck et al., 2010). Nevertheless, the Northwest region during winter emerges as the sole exception, with the affected area showing an upward trend. It can be argued that a persistent increase in arson has tended to extend the surface affected in this area (Ganteaume et al., 2013). Finally, positive trends are detected in winter in the number of human fires in the Northwest and Hinterland regions (both summer and winter), contrasting with a decrease found in the Mediterranean region. Human-burnt area follows a positive trend mainly during winter in the Northwest and in many areas in the south, whereas during summer a decrease is more widespread. This fact suggests that summer human-burnt area is declining, but intensifies during winter. The reasons which may explain this fact could relate to a continuance of arson attacks as a common practice which still remains. To our knowledge, this is the first analysis of fire frequency and burned area based on the source of the fire. Therefore, we cannot establish any comparison.

Downscaling to NUTS3/provincial level, Sen's slope has exposed the underlying spatial heterogeneity in the magnitude of the trends, both positive and negative (Fig. 4). In this respect, number of fires is the feature with the highest degree of change. Trend magnitude in the number of fires appears to be distributed along a west-to-east gradient, starting 
with increasing dynamics in the west and ending with downward trends in the eastern Mediterranean provinces. In contrast, the sharpest decreases are observed in features relating to burned areas such as burned area, burnt area during summer and human-burnt area during summer. However, this behaviour is reversed during winter, although trend magnitude is less marked. This is probably due to the improvement in fire extinguishing or encouraging monitoring and prevention (MAPA, 1988; Rodrigues et al., 2016), particularly encouraged during summer. Fires ignited by lightning perhaps show the most contrast as there is a marked dichotomy between west and northeast. For instance, decreasing dynamics are found in the northeast area, whereas major upward trends are situated in the western half of the region, which is considered one of the most lightning-ignition-prone areas of Spain (Ortega et al., 2012). According to our results, there seems to be increased fire activity from natural causes. However, trends are more noticeable in the number of natural fires than in natural burned area, thus the average size of lightningcaused fires seems to be shrinking. It is important to note that other seasonal partitions like those reported by Moreno et al. (2014), Sousa et al. (2015) and Trigo et al. (2016) have been explored, finding almost no differences.

Finally, PCA-VR enables trends to be grouped to provide an easily readable description and characterization of fire regime at provincial level, also clarifying the spatial pattern of key fire trends. Therefore, we extracted four main components (see Table 4, Figs. 5 and 6), i.e. four distinct temporal behaviours: winter fire frequency (PC1), summer burnt area (PC2), large fires (PC3) and natural fires (PC4). The first two components are associated with seasonal fire activity, whereas components 3 and 4 relate to intrinsic characteristics of wildfires, such as fire size and ignition source, respectively. $\mathrm{PC} 1$ has led to identifying winter frequency trends and human-caused frequency during winter as key trend features, while PC2 gathers trends from burned area features, but mostly summer trends (burned area and humanburnt area), indicating that summer fire dynamics might play a secondary role compared to winter, at least in terms of the strongest temporal trend. However, the last two PCs, large fires and natural fires trends, appear to be similarly important. In addition, a seasonal contrast is clearly evident between the Northwest region dynamics and the rest of mainland Spain (i.e. negative trends located mainly in Galicia).

\section{Conclusions and future work}

In this paper, we have explored spatial-temporal changes of several fire regime features in Spain at regional and provincial levels. To this end, we combined change point detection techniques, trend detection procedures and PCA, applied to fire data from 1974 to 2013. Our results suggest that two main trends based on seasonal differences can be distinguished: fire frequency during winter and burned area during summer. It is important to highlight that in both cases human cause is strongly correlated to the trends, and thus apparently changes in burned area and fire frequency are partially controlled by human-caused fires. Additionally, mapping SS and PCA results at NUTS3 level suggests different behaviour in the northwestern provinces, which return the highest values, in terms of both frequency (upward trends) and burnt area (downward trends).

Change detection suggests a main breakpoint in the temporal evolution of fire features around the late 1980s and in the first half of the 1990s. In contrast, the Mann-Kendall test on a regional scale has revealed that the Mediterranean region presents a high degree of negative trends in the majority of fire features, in contrast to the Hinterland and Northwest. According to Sen's slope, the main trends at NUTS3 level show high spatial-seasonal variability, and several trend gradients linked to the number of fires and naturally caused fires were detected. In this regard, overall fire frequency shows an upward tendency, particularly strong during winter, while the burned area exhibited a general downward trend.

The analysis of spatial-temporal trends opens new research lines. For instance, further evaluation is required to incorporate other benchmark spatial units to provide greater detail than found at provincial level (for instance, grid cells). Nevertheless, deeper insights into causes explaining temporal behaviour of the main fire regime features should be explored, especially those linked to weather conditions and land use changes. Finally, the role of small fires $(1<$ ha) can be included, thus enriching fire regime assessment in order to avoid potential bias caused by their exclusion. In any case, the analysis given in this paper should provide a useful reference to obtain spatially and temporally explicit assessment of fire regime changes, to help improve delimitation of homogenous fire regime areas and to gain a more complete overview of wildfire phenomenon.

Data availability. Fire data are available upon request to the Spanish Ministry of Agriculture, Fisheries and Environment. CLC is freely available from the European Environmental Agengy (EEA).

Competing interests. The authors declare that they have no conflict of interest.

Acknowledgements. The Spanish Ministry of Education has financed this work through FPU grant 13/06618. We are also grateful for the comments from anonymous reviewers who have improved the final paper.

Edited by: Rosa Lasaponara

Reviewed by: three anonymous referees 


\section{References}

AEMET: Iberian Climate Atlas, Agencia Estatal de Meteorología (España) and Instituto de Meteorología (Portugal), Madrid, Spain, 2011.

Alvarado, E., Sandberg, D. V., and Pickford, S. G.: Modeling large forest fires as extreme events, Northwest Sci., 72, 66-75, 1998.

Bogdan, M., Frommlet, F., Biecek, P., Cheng, R., Ghosh, J. K., and Doerge, R. W.: Extending the modified Bayesian Information Criterion (mBIC) to dense markers and multiple interval mapping, Biometrics, 64, 1162-1169, https://doi.org/10.1111/j.15410420.2008.00989.x, 2008.

Bonet, A. and Pausas, J. G.: Old field dynamics on the dry side of the Mediterranean Basin: patterns and processes in semiarid southeast Spain, in: Old Fields: Dynamics and Restoration of Abandoned Farmland, edited by: Cramer, V. A. and Hobbs, R. J., Island Press, Washington, DC, 247-264, 2007.

Brotons, L., Aquilué, N., de Cáceres, M., Fortin, M.-J., and Fall, A.: How fire history, fire suppression practices and climate change affect wildfire regimes in mediterranean landscapes, PLoS One, 8, 1-12, 2013.

Cardil, A. and Molina, D.: Large wildland fires in three diverse regions in Spain from 1978 to 2010, For. Syst., 22, 526-534, https://doi.org/10.5424/fs/2013223-03899, 2013.

Castellnou, M., Kraus, D., and Miralles, M.: Prescribed burning and suppression fire techniques: from fuel to landscape management, in: Best Practices of Fire Use - Prescribed Burning and Suppression Fire Programmes in Selected Case-Study Regions in Europe, edited by: Montiel, C. and Kraus, D., European Forest Institute, Porvoo, Finland, 3-16, 2010.

Chen, J. and Gupta, A. K.: Change in normal mean and variance, in: Parametric Statistical Change Point Analysis, Springer, New York, 38-56, 2000.

Chen, J. and Wang, Y.-P.: A statistical change point model approach for the detection of DNA copy number variations in array CGH data, IEEE-ACM T. Comput. Bi., 6, 529-41, https://doi.org/10.1109/TCBB.2008.129, 2009.

Falk, D. A., Heyerdahl, E. K., Brown, P. M., Farris, C., Fulé, P. Z., McKenzie, D., Swetnam, T. W., Taylor, A. H., and Van Horne, M. L.: Multi-scale controls of historical forest-fire regimes: new insights from fire-scar networks, Front. Ecol. Environ., 9, 446-454, https://doi.org/10.1890/100052, 2011.

Fernandes, P. M., Loureiro, C., Guiomar, N., Pezzatti, G. B., Manso, F. T., and Lopes, L.: The dynamics and drivers of fuel and fire in the Portuguese public forest, J. Environ. Manage., 146, 373-382, https://doi.org/10.1016/j.jenvman.2014.07.049, 2014.

Flannigan, M., Krawchuk, M., de Groot, W., Wotton, B., and Gowman, L.: Implications of changing climate for global wildland fire, Int. J. Wildland Fire, 18, 483-507, https://doi.org/10.1071/WF08187, 2009.

Ganteaume, A., Camia, A., Jappiot, M., San-Miguel-Ayanz, J., Long-Fournel, M., and Lampin, C.: A review of the main driving factors of forest fire ignition over Europe, Environ. Manage., 51, 651-662, https://doi.org/10.1007/s00267-012-9961-z, 2013.

Hinkley, D. V.: Inference about the change-point in a sequence of random variables, Biometrika Trust, 57, 1-17, 1970.

Hisdal, H., Stahl, K., Tallaksen, L. M., and Demuth, S.: Have streamflow droughts in Europe become more severe or frequent?, Int. J. Climatol., 21, 317-333, https://doi.org/10.1002/joc.619, 2001.
Horst, P.: Factor Analysis of Data Matrices, 1st Edn., Holt, Rinehart and Winston, New York, https://doi.org/10.2307/1421153, 1965.

Kaiser, H. F.: The varimax criterion for analytic rotation in factor analysis, Psychometrika, 23, 187-200, https://doi.org/10.1007/BF02289233, 1958.

Kaiser, H. F.: The application of electronic computers to factor analysis, Educ. Psychol. Meas., 20, 141-151, 1960.

Kasischke, E. S. and Turetsky, M. R.: Recent changes in the fire regime across the North American boreal region - spatial and temporal patterns of burning across Canada and Alaska, Geophys. Res. Lett., 33, 1-5, https://doi.org/10.1029/2006GL025677, 2006.

Kendall, M. G.: Rank Correlation Methods, 4th edn., Charles Griffin, London, 1975.

Killick, R., Fearnhead, P., and Eckley, I. A.: Optimal detection of changepoints with a linear computational cost, J. Am. Stat. Assoc., 107, 1590-1598, https://doi.org/10.1080/01621459.2012.737745, 2012.

Krebs, P., Pezzatti, G. B., Mazzoleni, S., Talbot, L. M., and Conedera, M.: Fire regime: history and definition of a key concept in disturbance ecology, Theor. Biosci., 129, 53-69, https://doi.org/10.1007/s12064-010-0082-z, 2010.

MAGRAMA, Ministerio de Agricultura, Alimentación y Medio Ambiente: Los Incendios Forestales en España. Decenio 1991-2000, Madrid, available at: http: //www.mapama.gob.es/es/desarrollo-rural/estadisticas/decenio_ 1991_2000_tcm7-349069.pdf (last access: 2 August 2017), 2002.

MAGRAMA, Ministerio de Agricultura, Alimentación y Medio Ambiente: Los Incendios Forestales en España. Decenio 1996-2005, Madrid, available at: http: //www.mapama.gob.es/es/desarrollo-rural/estadisticas/decenio_ 1996_2005_tcm7-349070.pdf (last access: 2 August 2017), 2007.

MAGRAMA, Ministerio de Agricultura, Alimentación y Medio Ambiente: Los Incendios Forestales en España. Decenio 2001-2010, Madrid, available at: http://www.mapama.gob.es/es/desarrollo-rural/estadisticas/ incendiosforestales2001-2010finalmod1_tcm7-349255.pdf (last access: 2 August 2017), 2012.

Mann, H. B.: Nonparametric tests against trend, Econometrica, 13, 245-259, https://doi.org/10.1017/CBO9781107415324.004, 1945.

MAPA: ORDEN de 21 de marzo de 1988 por la que se establece un Plan de Acciones Prioritarias contra los Incendios Forestales, BOE 72, 24 de marzo de 1988, Spain, 1988.

Moreno, M. V. and Chuvieco, E.: Characterising fire regimes in Spain from fire statistics, Int. J. Wildland Fire, 22, 296-305, https://doi.org/10.1071/WF12061, 2012.

Moreno, M. V. and Chuvieco, E.: Fire regime characteristics along environmental gradients in Spain, Forests, 7, 262, https://doi.org/10.3390/f7110262, 2016.

Moreno, M. V., Conedera, M., Chuvieco, E., and Pezzatti, G. B.: Fire regime changes and major driving forces in Spain from 1968 to 2010, Environ. Sci. Policy, 37, 11-22, https://doi.org/10.1016/j.envsci.2013.08.005, 2014.

Morgan, P., Hardy, C. C., Swetnam, T. W., Rollins, M. G., and Long, D. G.: Mapping fire regimes across time and space: Un- 
derstanding coarse and fine-scale fire patterns, Int. J. Wildland Fire, 10, 329-342, https://doi.org/10.1071/WF01032, 2001.

Moriondo, M., Good, P., Durao, R., Bindi, M., and Giannakopoulos, C.: Potential impact of climate change on fire risk in the Mediterranean area, Clim. Res., 31, 85-95, 2006.

Ortega, M., Saura, S., González-Avila, S., Gómez-Sanz, V., and Elena-Rosselló, R.: Landscape vulnerability to wildfires at the forest-agriculture interface: half-century patterns in Spain assessed through the SISPARES monitoring framework, Agroforest Syst., 85, 331-349, https://doi.org/10.1007/s10457-0119423-2, 2012.

Pausas, J. G.: Changes in fire and climate in the eastern iberian peninsula (Mediterranean Basin), Climatic Change, 63, 337-350, 2004.

Pausas, J. G. and Fernández-Muñoz, S.: Fire regime changes in the Western Mediterranean Basin: from fuel-limited to drought-driven fire regime, Climatic Change, 110, 215-226, https://doi.org/10.1007/s10584-011-0060-6, 2012.

Pausas, J. G. and Keeley, J. E.: A burning story: the role of fire in the history of life, Bioscience, 59, 593-601, https://doi.org/10.1525/bio.2009.59.7.10, 2009.

Pereira, M. G., Malamud, B. D., Trigo, R. M., and Alves, P. I.: The history and characteristics of the 1980-2005 Portuguese rural fire database, Nat. Hazards Earth Syst. Sci., 11, 3343-3358, https://doi.org/10.5194/nhess-11-3343-2011, 2011.

Pettitt, A. N.: A non-parametric approach to the change-point problem, J. R. Stat. Soc. C-Appl., 28, 126-135, 1979.

Pezzatti, G. B., Zumbrunnen, T., Bürgi, M., Ambrosetti, P., and Conedera, M.: Fire regime shifts as a consequence of fire policy and socio-economic development: an analysis based on the change point approach, Forest Policy Econ., 29, 7-18, https://doi.org/10.1016/j.forpol.2011.07.002, 2013.

R Core Team: R: a Language and environment for statistical computing. R Foundation for Statistical Computing, Vienna, Austria, http://www.R-project.org/, last access: 8 November 2016.

Rodrigues, M., San Miguel, J., Oliveira, S., Moreira, F., and Camia, A.: An insight into spatial-temporal trends of fire ignitions and burned areas in the European Mediterranean countries, J. Earth Sci. Eng., 3, 497-505, 2013.

Rodrigues, M., Jiménez, A., and de la Riva, J.: Analysis of recent spatial-temporal evolution of human driving factors of wildfires in Spain, Nat. Hazards, 84, 2049-2070, https://doi.org/10.1007/s11069-016-2533-4, 2016.

Ruffault, J. and Mouillot, F.: How a new fire-suppression policy can abruptly reshape the fire-weather relationship, Ecosphere, 6, 119, https://doi.org/10.1890/ES15-00182.1, 2015.

Salis, M., Ager, A. A., Finney, M. A., Arca, B., and Spano, D.: Analyzing spatiotemporal changes in wildfire regime and exposure across a Mediterranean fire-prone area, Nat. Hazards, 71, 13891418, https://doi.org/10.1007/s11069-013-0951-0, 2014.

San-Miguel-Ayanz, J., Rodrigues, M., de Oliveira, S. S., Pacheco, C. K., Moreira, F., Duguy, B., and Camia, A.: Land cover change and fire regime in the European Mediterranean Region, in: Post-Fire Management and Restoration of Southern European Forests, Springer, the Netherlands, Dordrecht, 21-43, 2012.

San-Miguel-Ayanz, J., Moreno, J. M., and Camia, A.: Analysis of large fires in European Mediterranean landscapes: lessons learned and perspectives, Forest Ecol. Manag., 294, 11-22, https://doi.org/10.1016/j.foreco.2012.10.050, 2013.

Schmuck, G., San-Miguel-Ayanz, J., Camia, A., Durrant, T., Santos de Oliveira, S., Boca, R., Whitmore, C., Giovando, C., Libertà, G., Corti, P., and Schulte, E.: Forest Fires in Europe 2010, JRC Scient, Joint Research Centre - Institute for Environment and Sustainability Eur 24910 EN, Luxemburg, 2010.

Scott, A. A. J. and Knott, M.: A cluster analysis method for grouping means in the analysis of variance, Biometrics, 30, 507-512, 1974.

Seijo, F. and Gray, R.: Pre-industrial anthropogenic fire regimes in transition: the case of Spain and its implications for fire governance in Mediterranean type biomes, Hum. Ecol. Rev., 19, 5869, 2012

Sen, P. K.: Estimates of the regression coefficient based on Kendall's Tau, J. Am. Stat. Assoc., 63, 1379-1389, 1968.

Serra, L., Juan, P., Varga, D., Mateu, J., and Saez, M.: Spatial pattern modelling of wildfires in Catalonia, Spain 2004-2008, Environ. Modell. Softw., 40, 235-244, https://doi.org/10.1016/j.envsoft.2012.09.014, 2013.

Sousa, P. M., Trigo, R. M., Pereira, M. G., Bedia, J., and Gutiérrez, J. M.: Different approaches to model future burnt area in the Iberian Peninsula, Agr. Forest Meteorol., 202, 11-25, https://doi.org/10.1016/j.agrformet.2014.11.018, 2015.

Spano, D., Camia, A., Bacciu, V., Malasa, F., Duguy, B., Trigo, R., Sousa, P., Venäläinen, A., Mouillot, F., Curt, T., Moreno, J. M., Zavala, G., Urbieta, I. R., Koutsias, N., and Xystrakis, F.: Recent trends in forest fires in Mediterranean areas and associated changes in fire regimes, in: Forest Fires under Climate, Social and Economic Changes in Europe, the Mediterranean and Other Fire-Affected Areas of the World, edited by: Moreno, J. M., FUME, Lesson Learned and Outlook, Adelaide, Australia, 6-7, 2014.

Trigo, R. M., Sousa, P. M., Pereira, M. G., Rasilla, D., and Gouveia, C. M.: Modelling wildfire activity in Iberia with different atmospheric circulation weather types, Int. J. Climatol., 32, 27612778, https://doi.org/10.1002/joc.3749, 2016.

Turco, M., Llasat, M.-C., von Hardenberg, J., and Provenzale, A.: Climate change impacts on wildfires in a Mediterranean environment, Climatic Change, 125, 369-380, https://doi.org/10.1007/s10584-014-1183-3, 2014.

Turco, M., Bedia, J., Di Liberto, F., Fiorucci, P., von Hardenberg, J., Koutsias, N., Llasat, M.-C., Xystrakis, F., and Provenzale, A. Decreasing fires in Mediterranean Europe, PLoS One, 11, e0150663, https://doi.org/10.1371/journal.pone.0150663, 2016.

Venäläinen, A., Korhonen, N., Hyvärinen, O., Koutsias, N., Xystrakis, F., Urbieta, I. R., and Moreno, J. M.: Temporal variations and change in forest fire danger in Europe for 1960-2012, Nat. Hazards Earth Syst. Sci., 14, 1477-1490, https://doi.org/10.5194/nhess-14-1477-2014, 2014.

Wu, H., Soh, L.-K., Samal, A., and Chen, X.-H.: Trend analysis of streamflow drought events in Nebraska, Water Resour. Manag., 22, 145-164, https://doi.org/10.1007/s11269-006-9148-6, 2008.

Zavala, G., Urbieta, I. R., Rieiro, I., Bedia, J., Gutiérrez, J. M., and Moreno, J. M.: Trends in number of fires and burned area and their relationships with climatic variables across regions in Spain during 1974-2008, in: International Conference on Fire Behaviour and Risk, Alguero, Italy, 2011. 